\title{
ESTUDOS
}

\section{Cooperativismo: alternativa viável para a gestão escolar? Um estudo de caso}

Gerrá Leite Correia de Araújo

Candido Alberto Gomes

\section{Resumo}

Analisa a Cooperativa de Ensino da Cidade de Goiás e o Colégio Alternativo, na cidade de Goiás, fundados em virtude da insatisfação de um grupo de pais de camadas sociais médias tanto com a escola pública quanto com a particular. O estudo de caso coletou dados por meio de observação, análise documental, entrevistas e grupos focais. Os resultados apresentam um estabelecimento em que todos os atores participam da gestão. Do ponto de vista pedagógico, alcança eficazmente a apropriação de conteúdos pelos seus alunos para concursos públicos e o acesso à educação superior, conforme as aspirações dos pais. As despesas revelam que a remuneração docente é a mais alta da comunidade, porém a contribuição financeira das famílias é menor que a mensalidade da escola privada.

Palavras-chave: ensino médio; ensino fundamental; custos educacionais; gestão participativa; cooperativismo educacional.

\section{Abstract \\ Co-operativism: a feasible alternative for school management?}

This research project focuses on an educational co-operative and its junior and senior high school in the city of Goiás, Brazil. It was founded as a result of parents' low level of satisfaction concerning both public and private schools. The case study analysed data from observation, documentary analysis, interviews and focus groups. The results reveal that all school actors participate in its management. From the educational perspective, the school effectively teaches the contents required by college entrance exams and other kinds of selection, according to the parents' aspirations. The teachers' salaries reach the highest level in the community, however, the families' financial contribution is lower than the private school's tuition and fees.

Keywords: secondary education; primary education; educational cost; participative management; educational cooperativism. 


\section{Introdução}

Nas últimas décadas o Brasil tem assistido à busca de alternativas para a gestão escolar, valorizando a organização e a participação da comunidade escolar. Movendo-se entre os pólos das escolas públicas e particulares em sentido estrito, existem alternativas intermediárias que merecem ser estudadas; uma delas é o cooperativismo escolar, que obedece a orientações filosóficas originadas no século 19. O presente trabalho focalizou uma das diversas experiências existentes no Brasil, um estabelecimento mantido por cooperativa, que oferece as últimas séries do ensino fundamental e o ensino médio. Quais as características da experiência, sobretudo no que se refere aos processos de gestão e às perspectivas dos envolvidos nessa experiência? Como se aplicam a filosofia, a doutrina e os princípios cooperativistas? Como são os processos da gestão? Como se apresentam as suas estruturas de financiamento e custos, quando comparadas com outros estabelecimentos?

\section{Existe espaço entre os pólos?}

A história recente da educação brasileira envolve, em grande parte, a ascensão da escola pública como dever constitucional a ser prestado diretamente pelo Estado. O programa do Manifesto dos Pioneiros da Educação Nova, de 1932, lançou as bases da mudança da paisagem educacional brasileira, que aflora em debates técnicos e, sobretudo, ideológicos, mais ou menos calorosos, até os dias de hoje, entre escola pública e escola particular (Romanelli, 1978). Um dos resultados foi a extensão crescente das redes públicas por todo o País, predominando em toda a educação básica, com exceção apenas da educação superior. Nos tempos mais recentes desta trajetória, particularmente a partir dos anos 80, manifestou-se com maior clareza no nosso continente a crise do Estado e o rompimento de estruturas administrativas sobre as quais foi construída a modernidade dos nossos países (Kliksberg, 2003, 2004; Xavier, Amaral Sobrinho, Marra, 1994; Colozzi, 2002). Além dos modelos participativos da gestão democrática nas escolas públicas, se estabeleceram três setores: o primeiro composto pelo poder público ou governo; o segundo formado pelo mercado; e o terceiro constituído de fundações, organizações não-governamentais e movimentos grupais, que geralmente refletem a mobilização da sociedade civil, ocorrida precisamente a partir dos anos 80, isto é, da "década (pelo menos economicamente) perdida”. Em outras palavras, o espaço entre os pólos público e particular se preencheu com maior número de alternativas, tendendo a formar uma espécie de gradiente, não isento de contradições internas.

Na verdade, o espaço intermediário deste gradiente não estava vazio. São muitas as semelhanças entre o terceiro setor e o cooperativismo na busca de soluções econômicas e sociais para os problemas que atingem as classes e grupos menos favorecidos. O cooperativismo possui precedentes nos "socialistas utópicos", tendo começado em 1844, quando foi fundada a Sociedade dos Equitáveis Pioneiros de Rochdale, na Inglaterra. Era uma cooperativa de consumo para melhorar as condições de vida dos trabalhadores da Revolução Industrial e, assim, emancipar o proletariado (Carneiro, 1981). O movimento passou da distribuição e consumo para os sistemas de produção, crédito, educação, serviços e outros setores. Seus princípios básicos se tornaram a adesão livre e aberta; o controle democrático pelos membros; a participação destes membros no capital da cooperativa; a autonomia e independência; o provimento de educação, treinamento e informação aos seus membros, gestores e empregados; a cooperação entre as cooperativas e o trabalho pelo desenvolvimento sustentável das suas comunidades (International Co-operative Alliance, 2006; cf. também Carneiro, 1981; Pinho, 1982). Desde as origens o movimento previa a constituição de um fundo para a educação dos cooperados e do público em geral, o que permite verificar que a educação estava inserida no seu cerne. Anos mais tarde surgiram as cooperativas intelectuais e recreativas, as escolares, as educacionais de pais e de alunos, as de trabalho cultural, as de profissionais da educação (Organização das Cooperativas Brasileiras, 2000) e o ensino do cooperativismo em vários níveis.

No Brasil o cooperativismo surgiu no início da República, com a constituição das primeiras cooperativas, no setor de consumo, ao final do século 19. Em 1902 ele chegou ao campo, por meio do padre jesuíta 
suíço Theodoro Amstadt, que organizou uma caixa de crédito rural (Pinho, 1982).

Por sua vez, o cooperativismo educacional teve raízes na primeira metade do século 20 na Europa, Estados Unidos, Brasil e outros países, que criaram cooperativas intelectuais e recreativas (Frola, 1937) e escolares (Luz Filho, 1960). O cooperativismo educacional tem como objetivos oferecer uma educação de qualidade, diminuir os seus custos, utilizar a gestão cooperativista e atuar de forma coletiva por meio da participação da comunidade escolar, com base na democracia e eqüidade.

Segundo Luz Filho (1960), a primeira cooperativa escolar fundada no Brasil data de 1933, na cidade de Cruzeiro, Estado de São Paulo, com berço e modelo franceses. Em 1958 o ramo já possuía 883 cooperativas escolares. Por meio do autoplanejamento, da auto-organização e da autogestão dos educandos se produzia, comercializava, poupava e comprava o que fosse necessário para os alunos e a escola, segundo um processo coletivo, educativo e prático, formando os cooperados para a vida prática, como planejadores, organizadores, gestores, produtores, poupadores, fiscais, etc.

O Estado, ao contrário, deve prosseguir com o seu papel constitucional. Segundo Pasquini (1992), as cooperativas não podem ser vistas apenas como forma de baratear os custos educacionais, isto é, como meras mantenedoras de escolas, mas como uma alternativa pedagógica para alunos, educadores e pais insatisfeitos com limitações de escolas existentes. A diminuição dos custos com o ensino virá como conseqüência do processo cooperativista aplicado ao setor.

A sua gestão é essencialmente democrática, graças à participação dos seus cooperados, com igualdade de direito a voz e voto, onde a decisão da maioria é de responsabilidade. A participação dos seus membros é simultaneamente um direito e um dever, privilegiando a participação daqueles que trabalham nessas organizações. No caso do Brasil, a filosofia, doutrina e princípios do cooperativismo estão consubstanciados na Lei ${ }^{0} 5.764$, de 16 de dezembro de 1971 (Brasil, 2006).

Entretanto, deve-se estar alerta a distorções destes ideais e princípios históricos, entre as quais citam-se as cooperativas organizadas com a intenção de simular uma situação pseudolegal, para extrair vantagens econômicas. Elas são formadas por pessoas que convencem os trabalhadores a se associarem a uma cooperativa de trabalho ou serviço, colocando condições, dados e situações irreais, além de ocultar as verdadeiras intenções dessas pessoas. Entre outras características, este tipo de cooperativa possui "donos" e se organiza com o interesse de usar os serviços dos cooperados e, ao mesmo tempo, fraudar e sonegar as obrigações legais em geral, particularmente trabalhistas e previdenciárias. Os "donos" tendem a se perpetuar na direção da cooperativa, para que possam manipular e controlar a sua gestão, elevando, assim, os seus interesses em detrimento daqueles dos cooperados (Camacho, 1997).

Mais ainda, o cooperativismo apresenta as suas contradições históricas. Respeitadas outras posições, ele poderia ser interpretado como uma alternativa pragmática, proposta no bojo do capitalismo, sem negálo nos fundamentos, porque é inevitável articular-se com o mercado. Propõe-se modificar as relações sociais e as relações com o capital, porém não se pode ignorar a competição no seu entorno, a obtenção de excedentes, etc., assim apresentando possibilidades e limites para a mudança (cf. Ribeiro, 2004). Estas contradições também se verificam em escolas cooperativas focalizadas pela literatura. Duas delas, por exemplo, nasceram basicamente da crise da escola pública, do avanço da organização da sociedade civil e da busca de menores custos pelas camadas médias urbanas. Numa foram detectadas as tensões entre os pioneiros idealistas e os demais cooperados, cujos objetivos eram mais "práticos", observando-se o choque entre valores cooperativos e competitivos (Gabbi, 2001). Em outra se evidenciou o campo contraditório entre o seu projeto pedagógico e educacional e o seu projeto político-econômico. Apesar desse terreno ambíguo, nela se encontraram espaços que traziam esperança de aprimoramento de conteúdos de formação humana (Mota, 2003).

\section{Objetivos e metodologia}

Ao se propor realizar um estudo de caso, esta pesquisa adota uma posição que há algum tempo seria considerada heterodoxa, especialmente em face da generalização dos dados. Como é amplamente 
reconhecido, cabe renunciar à representatividade clássica e optar pela "generalização naturalística”, isto é, em função do conhecimento experiencial do sujeito leitor, este indagará o que pode (ou não) aplicar deste caso na sua situação (Lüdke, André, 1986). Nesse sentido, a pesquisa supera a chamada ilusão indutiva, segundo a qual investigadores crêem que o seu trabalho consiste em demonstrar a generalidade de uma afirmação e se esgotam na vã e incessante procura da universalidade nos casos concretos. Na verdade, quando o verdadeiro trabalho científico constitui um sistema de interpretação pertinente para o real estudado (Lerbet, 2001).

A presente pesquisa se propôs identificar as características e analisar a experiência da Cooperativa de Ensino da Cidade de Goiás Ltda. (Coopecigo), da tipologia educacional "pais de alunos", mantenedora do Colégio Alternativo. Em coerência com a metodologia do estudo de caso, foi adotada a "amostragem intencional”, como um caso extremo (Quinn, 2000), rico de informações, por ser considerada bem-sucedida, inclusive pelo seu longo tempo de funcionamento, de 15 anos, e pela manifesta disposição de oferecer os dados necessários, inclusive da área financeira, estes últimos essenciais para os propósitos. O trabalho visou verificar o conhecimento e a aplicação da filosofia, doutrina e princípios cooperativistas e as perspectivas dos atores envolvidos. Além disso, buscou analisar a estrutura das despesas e a despesa média por aluno/ano. A coleta de dados em campo levou 20 dias úteis integrais, no período de março a abril de 2004, convivendo com os integrantes da Cooperativa e do Colégio. A análise documental focalizou a legislação e normas pertinentes, os estatutos, regimentos, regulamentos, livros de atas das diversas assembléias e conselhos, projeto político-pedagógico do Colégio, planos de curso, manuais dos estudantes e professores e outros. Foram realizadas entrevistas semi-estruturadas, com roteiros diferenciados, além de grupos focais. ${ }^{1}$ Os participantes foram escolhidos mediante sorteio, com uso de reposições, alcançando $60 \%$ do Conselho Administrativo, 65\% do Conselho Comunitário, 25\% dos professores, o diretor do Colégio, o coordenador pedagógico e o coordenador de turno, totalizando 26 participantes. Os grupos focais foram levados a efeito com alunos de uma turma do ensino fundamental e outra do ensino médio, ambas sorteadas. Vários alunos foram também entrevistados individualmente. Igualmente, foi realizado um grupo focal com cooperados. Ao todo houve 28 participantes.

\section{A cooperativa e o colégio}

A Coopecigo foi fundada em 1989, como cooperativa de pais de alunos, conjuntamente com o referido Colégio. Possuía 350 cooperados; Estatuto Social de acordo com a Lei anteriormente citada; Conselho Administrativo composto por dez cooperados, assim distribuídos: diretor presidente, diretor vice-presidente, diretor secretário, diretor financeiro, diretor de operações e cinco conselheiros, que se reuniam uma vez por ano em assembléia geral ordinária e, sempre que necessário, em assembléia geral extraordinária.

Tanto a entidade mantenedora quanto a mantida surgiram como alternativa às elevadas mensalidades escolares cobradas pelas escolas particulares e à deficiente qualidade da escola pública, segundo as expressões consensuais dos entrevistados. Ainda segundo estes, a Cooperativa e o Colégio reduziram os custos, na medida em que diminuíram a burocracia e se valeram da autonomia e da descentralização financeira. As decisões eram tomadas pelos cooperados em assembléias, por maioria, deixando de lado os processos decisórios verticais, atados à palavra final do proprietário, no caso de estabelecimento particular, ou do diretor e da Secretaria de Educação, com suas intrincadas legislação e normas, no caso da escola pública, mais uma vez de acordo com as percepções convergentes dos entrevistados. A descentralização financeira ocorria e ocorre através do rateio das despesas com os seus cooperados, sem que nessas despesas estivesse incluído qualquer lucro. Neste sentido, o caráter nãolucrativo tem o sentido da expressão constitucional (art. 213, I), observando-se a existência de excedentes financeiros, aplicados no próprio Colégio.

À época da coleta de dados, o Colégio Alternativo atendia a 130 alunos, a quem oferecia as quatro últimas séries do ensino fundamental e o ensino médio. O quadro pedagógico era formado por 18 professores e um bibliotecário, além do diretor e dois

\footnotetext{
As entrevistas de grupos focais, como são conhecidas e aplicadas também no Brasil, têm tipicamente seis características: 1) pessoas, 2) reunidas numa série de grupos, 3) possuem determinadas características e 4) provêem dados 5) de natureza qualitativa 6) numa discussão focalizada (Krueger, 1998).
} 
coordenadores, todos contratados como empregados celetistas, isto é, não eram cooperados. O quadro de auxiliares era composto de tesoureiro, secretário, porteiro, dois vigias e dois auxiliares de limpeza, também empregados celetistas. $\mathrm{O}$ projeto político-pedagógico, com tendências sociointeracionistas (construtivistas), incluía a filosofia, doutrina e princípios cooperativistas. Havia um conselho comunitário, composto de um pai, um aluno e dois professores representando cada turma, que se reunia na última quinta-feira de cada mês, nos termos regimentais.

O prédio, cedido pela Universidade Federal de Goiás, era composto por sete salas de aula, uma sala para professores, uma sala para coordenação, biblioteca, laboratório de ciências, áreas coberta e descoberta, campo de futebol e duas quadras alugadas.

\section{A organizacão e o funcionamento}

A Cooperativa e o Colégio, planejados de modo integrado, segundo se constatou, obedeciam a todas as exigências da legislação e normas pertinentes. As decisões tomadas pelos cooperados nas assembléias e nos Conselhos Administrativo e Comunitário eram implantadas pela direção do Colégio. O Estatuto, regimentos e projetos foram elaborados de modo compartilhado.

Os conhecimentos sobre a filosofia, a doutrina e os princípios cooperativistas apareciam em todo o Estatuto da Cooperativa, não sendo, porém, devidamente explicitados no Regimento, nos planos de curso e no Regulamento do Conselho Comunitário do Colégio. No entanto, por meio das entrevistas com os participantes sobre os princípios cooperativistas mais importantes, verificou-se que eles eram percebidos como a democracia, a participação, a partilha, a interação, a atividade comunitária, a gestão democrática, a união em torno de um objetivo comum e a colaboração e a construção coletivas. Na visão dos alunos, estes princípios eram a união, a ajuda mútua, a participação, a luta por um bem comum e a colaboração. Já os pais integrantes do Conselho Comunitário deram ênfase aos princípios da cooperação, integração, participação e união. Assim, apesar de os diretores terem conhecimentos mais pormenorizados, os diversos atores convergiam nos princípios, sugerindo o conhecimento e a possível internalização da filosofia cooperativista. Ainda assim, notou-se nos sujeitos pesquisados a necessidade de conhecimentos mais profundos sobre o cooperativismo, o que dificultava a sua aplicação em favor da gestão e da educação, constituindo obstáculo à participação de todos na comunidade escolar.

As assembléias e reuniões tratavam de assuntos mais ligados à gestão geral da Cooperativa e do Colégio, como contratação de funcionários, do diretor do Colégio, aprovação da contratação de professores, salários, compra de materiais e equipamentos, despesas de manutenção e conservação e também de ações pedagógicas a serem efetuadas, como passeios, rádio interna, festas e jogos. As reuniões do Conselho Comunitário do Colégio analisavam e discutiam as decisões das assembléias e reuniões da Cooperativa, juntamente com os demais problemas pedagógicos. Os assuntos mais freqüentemente tratados eram o rendimento de turmas e alunos, problemas de indisciplina, conteúdos a serem trabalhados, interdisciplinaridade, plantão pedagógico, preparação dos alunos para o ingresso em cursos superiores, festas, jogos, visitas a outras cooperativas educacionais, necessidade de montar laboratório e oferecer cursos de informática, construção e aprimoramento do projeto pedagógico e maior rigidez na disciplina dos alunos, como as regras de não fumar, namorar ou trazer amigos para o interior do Colégio.

Por sua vez, os alunos enfatizaram que as decisões eram tomadas por meio da $\mathrm{CO}$ locação dos problemas, do que é preciso fazer ou resolver, discussões sobre os mesmos, onde se tem a participação dos alunos, coordenadores, diretora e pais. Num grupo focal uma aluna da sétima série assim se expressou:

- No nosso Colégio quem toma as decisões são os pais, os professores e os alunos. Todos os meses temos um conselho comunitário que reúne representantes dos pais, dos professores e dos alunos para discutirmos como vai a educação no Colégio. (Aluna da $7^{\mathrm{a}}$ série)

Também os professores enfatizaram o caráter participativo das decisões, como um docente que declarou: 
- O diferencial desta escola em relação às outras está no poder de decisão. Tudo aqui é discutido, pesado e analisado para chegarmos a uma decisão melhor para todos. Aí está a diferença da administração da escola particular, onde tudo é decidido pelos donos e, na escola pública, o diretor é quem manda. (Membro do corpo docente)

Por sua vez, em grupo focal de cooperados, uma manifestação típica foi que nas assembléias e reuniões pode-se falar à vontade, discutir os assuntos do Colégio. Somos livres para perguntar, ter acesso aos documentos, caso precise, aqui tudo é aberto a todos.

Desse modo, os documentos e as entrevistas com diferentes grupos convergiram para um ponto: que a gestão estava baseada na participação democrática da comunidade escolar, independentemente do seu capital social, de acordo com os princípios cooperativistas.

Nas entrevistas com os cooperados foi transmitida a idéia de que o Colégio não era algo dos outros, mas dos cooperados. Não se verificaram comportamentos de clientes cobrando direitos em relação aos serviços prestados, mas de pessoas que tomavam os problemas como coletivos, requerendo a sua participação. As declarações revelaram significativa coerência em torno de diversas características positivas do Colégio, como o incentivo à leitura; o desenvolvimento de competências, a exemplo da responsabilidade; o fato de ser conceituado como um dos bons colégios da cidade (o que foi corroborado por depoimentos de diversas pessoas da comunidade); o quadro de professores qualificados; o rigor na disciplina; o ensino participativo, mas exigente; os altos índices de classificação no ingresso na educação superior e em concursos públicos e o bom relacionamento social.

Afirmações feitas em grupos focais de cooperados representam bem duas aspirações dos pais: de um lado, a preocupação com a apropriação dos conteúdos programáticos e, de outro, a ordem na escola. Apesar do projeto político-pedagógico, constatou-se, na prática, uma escola disciplinadora e transmissora de informações, estas ligadas à preparação para concursos e processos seletivos de acesso à educação superior, preferentemente pública:
- Aqui os alunos estudam todos os conteúdos, completos, aqui os alunos estudam de verdade. É uma escola responsável, onde eu tenho confiança pela rigidez na disciplina e atenção com os alunos. (Cooperado, pai de aluno)

- Eu percebo a direção, coordenadores e professores sempre buscando novidades e melhorias, sempre interessados em ensinar mais e mais para os alunos, o que não ocorre na escola pública. (Cooperado, pai de aluno)

Percebe-se a valorização do caráter propedêutico do ensino e da apropriação de conteúdos como fatores de êxito na vida social. Portanto, se a formação dos educandos é importante, a informação, ou seja, o domínio daqueles conteúdos de maior relevância deixa os cooperados satisfeitos. Quanto à disciplina, observouse que as normas eram consistentemente aplicadas, o que se verificava, inclusive, pela não existência de pichação e depredação das dependências internas e externas, pela conservação dos banheiros e pelo cuidado com os equipamentos, inclusive da rádio interna, cuja programação era feita pelos alunos.

\section{O colégio visto pela direção}

A diretora do Colégio e a coordenadora pedagógica foram escolhidas pelo Conselho Administrativo da Cooperativa. Por sua vez, a coordenadora de turno foi selecionada pela diretora do Colégio. As escolhas dos profissionais eram efetuadas coletivamente pela Cooperativa ou pelo Colégio, ou ambos, com ratificação coletiva.

Sobre a gestão do Colégio, as entrevistadas fizeram declarações que enfatizaram o seu caráter participativo, como no exemplo abaixo:

- As tomadas de decisões, os problemas do Colégio e demais coisas em relação ao administrativo e ao pedagógico são resolvidas coletivamente pelo Conselho Administrativo da Coopecigo ou pelo Conselho Comunitário do Colégio. São sempre decisões que envolvem a todos, a menos que seja um problema corriqueiro, que é da minha competência resolver. O Conselho Administrativo e 
o Conselho Comunitário são suportes para a direção e eu cumpro o que a maioria decide. (Membro do grupo diretivo)

A análise documental e a observação evidenciaram também que as decisões eram tomadas coletivamente em reuniões e assembléias, após questionamentos, discussões e análise de problemas. Em relação ao que precisava melhorar no Colégio quanto à gestão e ao ensino-aprendizagem, as entrevistadas foram unânimes em citar a necessidade de uma sede própria e de um laboratório de informática e, ainda, de maior participação dos pais em todas as reuniões da Cooperativa e do Colégio.

Do ponto de vista da direção, o estabelecimento diferia dos públicos e particulares:

- A gestão da Cooperativa e do Colégio planeja e faz acontecer, isso influi diretamente no ensino-aprendizagem (...). Justamente nas tomadas de decisões é que o Colégio é diferente dos outros. As decisões aqui são coletivas (...). Decidimos coletivamente em função do que é melhor para a maioria. (Membro do grupo diretivo)

No que tange ao processo de ensino-aprendizagem, verificaram-se divergências entre, de um lado, o que constava do projeto político-pedagógico e as declarações em entrevistas do grupo diretivo e, de outro lado, a prática observada nas salas de aula e as entrevistas de outros atores. A abordagem sociointeracionista, segundo expressões do projeto, preconiza uma prática educativa para formar o educando enquanto pessoa humana dotada de autonomia intelectual e capacidade crítica para lidar com a realidade social, de criatividade, de capacidades múltiplas de inteligências e inspiração nos valores universais do cooperativismo e da solidariedade humana. Todavia, estas posições divergiam dos planos de curso, que, embora baseados nos Parâmetros Curriculares Nacionais, tinham objetivos explícitos de apropriação, acumulação e utilização do conhecimento na vida futura. Tanto as observações das atividades letivas quanto os depoimentos dos atores indicaram que, ao contrário do proclamado no projeto, as expectativas e a realidade de sala de aula estavam voltadas não para construir o conhecimento, mas para apropriar-se dos conteúdos. O projeto político-pedagógico dificilmente poderia realizar-se na prática, pois não atendia às aspirações dos pais, que valorizavam a acumulação daqueles conteúdos, de modo que os alunos pudessem obter o êxito em concursos e processos seletivos.

\section{O colégio visto pelos professores}

Os professores destacaram que a gestão envolvia a presença de todos os segmentos do Colégio e que as decisões eram tomadas democraticamente pela maioria e acatadas por todos, a exemplo da declaração abaixo:

- Quanto à administração, ela não é imposta e, sim, discutida e definida entre todos. [...] Usamos muito da ajuda mútua entre os professores, pois todos têm o mesmo objetivo... (Membro do corpo docente)

A principal diferença apontada pelo corpo docente em face de outros estabelecimentos era a autonomia, aliada ao poder de decisão, onde "tudo é discutido, pesado e analisado...”. Em relação à educação e ao ensino-aprendizagem, percebeu-se entre os professores satisfação quanto ao atendimento das suas solicitações e à disponibilidade de material didático, bem como a valorização da sua formação inicial e continuada. Com efeito, esta última ocorria por meio de seminários, palestras e cursos de curta duração realizados nas dependências da própria unidade educacional. Também se verificou reiteradamente, nas salas dos professores e da coordenação, a troca de idéias, com o planejamento conjunto de conteúdos a serem trabalhados de modo interdisciplinar.

Deve ser reiterado que os professores e outros funcionários não eram cooperados (o que evitaria os encargos trabalhistas), mas empregados da Cooperativa. Seus salários eram mais altos que os das escolas particular e públicas da comunidade. Afirmava-se que, não havendo lucro ou publicidade para atrair alunos, os recursos eram suficientes para melhor remuneração do magistério. 


\section{O colégio visto pelos alunos}

As declarações dos alunos valorizaram a qualidade do processo de ensinoaprendizagem e o rigor da avaliação. Tais exigências, porém, davam lugar a percepções variadas, como a de uma aluna da sétima série, que concordava com a qualidade do Colégio, mas considerava as tarefas excessivas:

- Eu e meus pais achamos que este Colégio é o melhor. $\mathrm{O}$ que eu não gosto muito daqui é porque passam muitas tarefas para casa. [...]. Outra coisa que eu não gosto é porque nossos pais e professores querem que a gente aprenda muito sobre tudo e estejamos sempre lendo um livro. (Aluno do ensino fundamental).

Os discentes externaram o consenso de que se tratava de um estabelecimento exigente, atencioso e cuidadoso com os alunos, a começar pelos cooperados, seus pais, apesar de às vezes se perceberem falhas no campo motivacional. A disciplina não raro era criticada ("a direção vigia a gente como crianças, todo mundo aqui manda na gente, pega no pé e qualquer coisa ligam para os nossos pais"), mas também era valorizada, considerando-se o Colégio como "o mais disciplinado da cidade". A participação discente, por meio das reuniões do Conselho de Classe e do Conselho Comunitário, foi outro aspecto considerado favorável e diferenciador de outras escolas, com impacto sobre o interesse nos trabalhos, que muitas vezes eram organizados em conjunto. Alguns entrevistados salientaram que em outros colégios nunca haviam participado de reuniões, nem tomado decisões coletivamente. Conforme um aluno, "aqui não tem uma só pessoa que resolve tudo". E uma representante de turma, sentindo-se protagonista do processo, disse: "eu reúno os elogios, as reclamações, os pedidos e levo para o Conselho".

Os professores eram considerados assíduos e capacitados, o que muitas vezes não ocorreria na rede pública, segundo alguns entrevistados. No entanto, refletindo as contradições já mencionadas entre o projeto político-pedagógico, os planos de curso e as práticas de sala de aula, os alunos destacaram a qualidade do ensino, mas esta foi definida como a apropriação e o acúmulo de conhecimento sistematizado.
Por sua vez, esta qualidade, repetindo as aspirações dos pais, foi vista como a chave para o sucesso na vida futura, marcada por concursos, processos seletivos de ingresso na educação superior e transferência para outras unidades educacionais, na capital do Estado.

\section{As despesas educacionais do colégio}

As questões dos custos e da nãolucratividade são tratadas desde o surgimento do cooperativismo e constituem parte integrante da sua filosofia, doutrina e princípios. Um estabelecimento educacional que não visa ao lucro deve ter custos mais baixos para as famílias dos alunos, um dos objetivos dos cooperados, que, no caso pesquisado, eram profissionais liberais, fazendeiros e funcionários públicos, entre outros, e que buscavam diferenças de qualidade e de custos em relação às redes escolares do município.

Os pesquisados concordaram, em suas declarações, quanto à estimativa da composição dos cooperados e dos alunos com relação ao nível socioeconômico. Segundo eles, não havia cooperados e alunos de níveis "alto" e "baixo". Cerca de $30 \%$ eram de nível "médio alto"; $50 \%$, de nível "médio médio" e 20\%, de nível "médio baixo". Portanto, a seleção social eliminava da Cooperativa e do Colégio as camadas populares, que não podiam pagar as despesas, mesmo mais baixas que as de uma escola particular usual. Situação semelhante tinham outras escolas cooperativas focalizadas pela literatura (Gabbi, 2001; Mota, 2003). Desse modo, a escola não precisava fazer face a obstáculos mais significativos quanto ao capital cultural e à integração à cultura escolar, o que não ocorre na rede pública. Também havia relativa homogeneidade de aspirações socioeducacionais elevadas, que se expressavam repetidamente e influíam no processo de ensino-aprendizagem, considerando a escolarização um canal de mobilidade social ascendente.

De que maneira este grupo, que passou por certo filtro social, conseguia reduzir os custos educacionais? Como os cooperados têm como objetivo o suprimento da necessidade de bens ou serviços, a educação tende a se fazer por custos mais 
baixos. A legislação isenta as cooperativas de certos impostos, abrangendo os resultados dos atos cooperativos, ou seja, os atos ocorridos entre a cooperativa e os seus cooperados. Dependendo do tipo de cooperativa, podem deixar de ser pagos os impostos de Renda, sobre serviços, sobre a circulação de mercadorias e serviços de transporte e comunicação e outros. Havendo caráter não-lucrativo, no sentido antes indicado, e isenções fiscais, era feito o rateio das despesas entre os cooperados. Estas eram controladas pelo Conselho Administrativo da Cooperativa, que tomava providências relativamente simples de economia, como, por exemplo, a circulação dos livros adquiridos entre os alunos sob a forma de rodízio. Os estabelecimentos particulares, como foi declarado por cooperados, geralmente "têm menos foco nos pais e buscam atender, antes de tudo, professores, livreiros e editores" (Cooperados em grupo focal).

Não havendo condições de calcular os custos, foram obtidos os dados das planilhas do Colégio, que compreendem as suas despesas, do ponto de vista contábil (Tabela 1). Os dados, tais quais constam dos documentos fornecidos, incluem muitos números redondos, sugerindo que são estimativas ou um orçamento preliminar. Cabe esclarecer que se consideraram os salários brutos mensais e anuais, incluindo todos os encargos trabalhistas correspondentes e eventuais

Tabela 1 - Colégio Alternativo Distribuição das despesas por categoria - 2003

Especificação
Despesas com pessoal:

Diretor

Coordenador pedagógico

Coordenador de turno

Tesoureiro

Secretário

Professores (18)

Porteiro

Vigias (2)

Auxiliares de limpeza (2)

Serviços de terceiros

TOTAL PARCIAL

Material de consumo:

Material didático

Material de enfermaria

Material esportivo

Material de limpeza

Material de uso geral

Outros

TOTAL PARCIAL

Outras despesas:

Água, energia e telefone

Contribuição sindical

Encargos e taxas

Manutenção

TOTAL PARCIAL

TOTAL GERAL

Fonte: Planilhas do Colégio Alternativo.

Em R\$ (valores nominais)

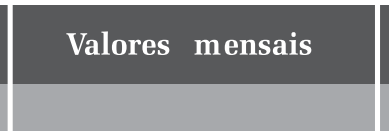

$1.172,00$

696,00

300,00

813,00

510,00

$8.910,00$

350,00

620,00

480,00

300,00

$14.151,00$

500,00

50,00

100,00

100,00

400,00

450,00

$1.600,00$

500,00

150,00

550,00

125,00

$1.325,00$

$17.076,00$
Valores anuais

$15.626,66$

$9.280,00$

$4.000,00$

$10.840,00$

$6.800,00$

$18.800,00$

4.666,66

$8.266,66$

$6.400,00$

$4.000,00$

$188.679,98$

$6.000,00$

600,00

$1.200,00$

$1.200,00$

$4.800,00$

$5.400,00$

$19.200,00$

$6.000,00$

$1.800,00$

$6.600,00$

$1.500,00$

$15.900,00$

$223.779,98$ 
gratificações. Isso, aliás, caracteriza a verdadeira cooperativa, em vez de entidades artificiosas que obrigam os trabalhadores a ser "cooperados" e a fazer descontos da sua remuneração para fugir às obrigações trabalhistas e previdenciárias. Foram também incluídos os honorários da diretoria da Cooperativa, pagos sob a forma de pró-labore, por se tratar de sociedade cooperativista, de acordo com a citada Lei $\mathrm{n}^{0} 5.764$, de 16 de dezembro de 1971 (Brasil, 2006). Sendo estes os únicos dados disponíveis, deve-se considerá-los como uma aproximação razoável da realidade.

A Tabela 1 deixa claro que a maior parte das despesas se refere ao corpo docente. Com efeito, o mínimo salário por hora-aula de uma cooperativa educacional é estabelecido pela Organização das Cooperativas Brasileiras e, no exercício de 2003, foi de $\mathrm{R} \$ 8,00$. Na Cooperativa em foco, o valor da hora-aula era de $\mathrm{R} \$$ 8,70 e o salário médio mensal bruto por professor, de R 4995 por uma média de dez horas-aula semanais. Este vinha a ser o maior valor pago na cidade, uma vez que a rede estadual remunerava a hora-aula por $\mathrm{R} \$ 4,00$ e o outro estabelecimento particular (que só oferecia o ensino fundamental), por R $\$ 7,00$. Neste último a média salarial era maior, isto é, de R\$ 600,00 para 20 horas semanais.

O Colégio Alternativo tinha em média 19 alunos por turma e oito alunos por professor. Estas médias foram consideradas pelos entrevistados como positivas para o sucesso do ensino-aprendizagem, permitindo que os professores dispensassem mais tempo para cada aluno (o que foi corroborado pelas observações). Deve-se consignar que, para a literatura internacional, é controvertida a associação entre o número de alunos por turma e o rendimento escolar, em geral apontando-se desvantagens para turmas muito grandes e muito pequenas (Gomes, 2005). Segundo cálculos com dados originais do Censo Escolar de 2003 (Inep/MEC), na rede estadual de Goiás a média de alunos por turma era de 59,5 e, na rede particular, era de 38,4 . Já as médias de alunos por função docente eram, de 21,6 e 13,6 nas redes pública e privada, respectivamente. O Colégio enfocado pela presente pesquisa se situava muito abaixo dessas médias, porém, na percepção dos informantes, não indicava capacidade ociosa, pois a sua função era atender satisfatoriamente aos filhos dos cooperados. De qualquer forma, deve-se reconhecer que um número maior de alunos permitiria um rateio das despesas a menor para os cooperados. Permitiria também arrecadar mais recursos para investimento, de modo a resolver a questão de o estabelecimento funcionar em prédio cedido.

Quanto ao material de consumo e às outras despesas, eram muito menores que as do pessoal, com destaque para material didático, encargos e taxas e água, energia elétrica e telefone. A Tabela 2 indica que a despesa com o pessoal docente correspondia a quase a metade e com o pessoal não-docente a quase um terço do total. O pessoal era responsável, ao todo, por $84,32 \%$ das despesas estimadas. Numa pesquisa sobre o ensino médio público, os salários totais variaram de $85,11 \%$ a 90,21\% do custo/aluno (Brasil, 2002). Note-se, porém, que despesas não são custos e que, mesmo em se tratando destes últimos, há diversas metodologias de apuração, sem unanimidade de resultados.

Dividindo-se a despesa total estimada pela matrícula, chega-se à despesa por aluno/mês de R\$131,35. Levando em

\section{Tabela 2 - Colégio Alternativo Distribuição das despesas anuais por categoria em valores absolutos e percentuais- 2003}

\begin{tabular}{l|c|c}
\multicolumn{1}{c}{ Categorias } & Valores em R\$ & (nominais) \\
\hline Pessoal docente & $118.800,00$ & $\%$ \\
\hline Pessoal não docente & $69.879,98$ & 53,10 \\
\hline Material de consumo & $19.200,00$ & 31,22 \\
\hline Outras despesas & $15.900,00$ & 7,58 \\
TOTAL & $223.779,98$ & 100,00
\end{tabular}

Fonte: Planilhas do Colégio Alternativo. 
consideração as estimativas anuais das planilhas, que parecem mais aproximadas da realidade, o valor seria de $\mathrm{R} \$ 1.721,38$ por aluno/ano. Como, porém, considerar o valor da cessão do prédio? Conforme avaliação obtida na comunidade, o aluguel suposto a ser pago, a preço de mercado, por uma edificação semelhante à cedida seria de R\$ 800,00 mensais. Acrescentando-se este montante, a despesa média aluno/ano passaria a ser de $\mathrm{R} \$ 1.795,23$, sem incluir o valor dos móveis e equipamentos.

A título de comparação simplesmente ilustrativa, convém citar que o custo/ aluno no ensino médio público, apurado por pesquisa de campo realizada em 2001 (Brasil, 2002), segundo outra metodologia, variou de $\mathrm{R} \$ 301,44$ a $\mathrm{R} \$ 592,86$ (ou, respectivamente, a $\mathrm{R} \$ 375,02$ e $\mathrm{R} \$ 737,58$ a preços de 2003, com a correção pelo IPCAIBGE). Os custos muito mais baixos que as despesas do Colégio Alternativo parecem se dever em grande parte às vantagens da economia de escala. A menor matrícula dos estabelecimentos incluídos naquele relatório foi de 1.604 alunos. A média de alunos por turma foi de 37 a 48, enquanto a média de alunos por professor ficou entre 24 e 36 . Por outro lado, a média de funcionários não-docentes por aluno teve a variação de 59 a 115, ao passo que no Colégio Alternativo esta proporção era de 10. Além disso, o custo salarial médio docente por hora, na citada pesquisa sobre o ensino médio, situava-se entre $\mathrm{R} \$ 2,95$ e $\mathrm{R} \$ 8,13$ (R\$ 3,67 e R\$ 10,11, respectivamente, segundo a correção para 2003 pelo IPCA-IBGE).

Como o Colégio Alternativo, numa cidade de porte médio, pagava $\mathrm{R} \$ 8,70$ por hora-aula, os seus professores eram relativamente muito bem remunerados, apesar da pequena matrícula e das reduzidas médias de alunos por professor e por funcionário. Apesar de todas as diferenças, é provável que a gestão da Cooperativa, o seu caráter não lucrativo e as isenções fiscais (que, entretanto, não cobriam os encargos trabalhistas) contribuíssem para que, apesar da despesa média elevada, os professores alcançassem tal nível salarial, sendo correspondentemente exigidos no seu trabalho pelas direções do Colégio e da Cooperativa.

Outra questão se refere aos preços pagos no mercado local pelos pais e a despesa média aluno/mês do Colégio Alternativo. Esta despesa já foi estimada em R\$131,35.
Acrescentando-se o aluguel suposto, chega-se a R\$137,51. À época da coleta de dados, foi informado que os pais pagavam dez parcelas mensais de $\mathrm{R} \$ 175,00$ tanto para o ensino fundamental quanto para o médio. Multiplicando-se pela matrícula, teríamos R\$227.500,00, o que superaria a despesa total de 2003 em 1,66\%. Pela legislação, as despesas são rateadas entre os cooperados.

O único estabelecimento particular da cidade, de natureza confessional, cobrava a mensalidade de $\mathrm{R} \$ 195,00$ pelas quatro últimas séries do ensino fundamental. Se fosse oferecido o ensino médio, tal mensalidade seria maior. Embora não tivessem sido apurados os números exatos, as médias de alunos por turma e alunos por professor eram bem mais altas. Apenas a título ilustrativo, a mensalidade do Colégio Alternativo era $10,26 \%$ mais baixa que a daquele estabelecimento, e a despesa média estimada por aluno/mês do primeiro ( $R \$ 137,51$ ) ficava $29,48 \%$ abaixo da mensalidade do segundo.

\section{Conclusões}

A Cooperativa, pelas evidências, organiza-se em bases participativas, objetivando não só suprir seus cooperados de bens e serviços educacionais, como também realizar determinados programas educativos e sociais. Sua organização e funcionamento, apesar de indicações de que a participação nas reuniões deveria ser maior, eram coerentes com os princípios cooperativistas. Havia, porém, indícios de que os cooperados tinham certas restrições em relação a efetuar maiores investimentos, como, por exemplo, a construção de nova sede e a constituição do laboratório de informática.

Quanto à estimativa da despesa média aluno/ano, é aparentemente muito mais elevada que o custo dos estabelecimentos públicos pesquisados em 2001 (Brasil, 2002), por ser um estabelecimento relativamente pequeno, que não se valia de modo amplo das vantagens da economia de escala. Entretanto, os cooperados pagavam menos do que se tivessem os filhos numa unidade escolar privada stricto sensu. As turmas eram menores e os professores não só percebiam o maior salário por hora-aula do município como só em dois casos eram menos remunerados que 
os seus colegas das escolas públicas investigadas em todo o País (Brasil, 2002).

Os processos de participação eram ativos para os diferentes atores integrantes da comunidade escolar. A reputação do Colégio na comunidade era elevada, tanto pelo aproveitamento dos alunos e a sua aprovação em processos seletivos em geral como pelo rigor da disciplina. Os cooperados se revelavam satisfeitos porque o objetivo de preparar os alunos para a vida, tal como a concebiam, era atingido, apesar da proclamação de um ideário pedagógico diferente. A prática pedagógica acabava sendo modelada pelas expectativas dos cooperados, tornando as teorias esposadas apenas valores proclamados. Sendo à época o único estabelecimento particular a oferecer o ensino médio na cidade, o fato de não escolher a escola pública levaria parte significativa do seu alunado a estudar em Goiânia. Esta mudança significaria elevar as despesas indiretas com a educação, com aluguel de habitação, transporte, alimentação e outras. Portanto, pelas indicações verificadas, os objetivos eram alcançados.

A Cooperativa e o Colégio podem ser vistos como meios de maximizar a relação custos-benefícios em favor de um projeto de ascensão social de grupos pertencentes às camadas médias da população. Os cooperados conseguiam pagar menos por uma educação por eles acompanhada e, de certo modo, dirigida e supervisionada. Esta educação tinha como alvos a conservação ou a elevação do status das famílias na geração seguinte por meio do acesso a cargos públicos por concurso e por meio da continuidade dos estudos em nível superior. Neste sentido, a disciplina era uma das suas tônicas. As contradições entre ideário pedagógico escrito e a sua prática, entre os princípios do cooperativismo e a ampla participação dos cooperados, entre a oferta de educação a custos mais baixos e a protelação de investimentos importantes se apresentam de modo semelhante às ambigüidades de outras escolas cooperativas e do próprio cooperativismo.

Entre as questões que se pode propor à reflexão está a de que a escola pública, apesar da determinação constitucional da gestão democrática, na percepção de entrevistados, parecia centrada no diretor e na Secretaria de Educação.
Estes, de modo geral, consideraram que a participação na Cooperativa e no Colégio era muito maior que nos setores público e particular e que os professores podiam ser cuidadosamente monitorados. Se os mesmos recursos financeiros fossem entregues à escola pública, seriam obtidos idênticos resultados? Certamente não. Mesmo que a gestão fosse revolucionada, as barreiras burocráticas vencidas e o porte da escola pública alterado, seria ingênuo supor que o modelo pudesse ser tão ampliado. Como se frisou, o Colégio em tela não conta com as camadas populares e os problemas de capital cultural e adequação da escola, de maneira inclusiva, a um alunado heterogêneo. A Cooperativa é um projeto de camadas sociais médias, ao passo que a escola pública deve ser universal e lidar com diversidades muito mais amplas, inclusive de aspirações educacionais e ocupacionais. De qualquer forma, pode ser registrado um paradoxo: a Cooperativa e o Colégio foram criados como alternativa às escolas públicas e particulares. No Colégio a gestão era mais democrática e o protagonismo de pais e alunos, maior que na escola pública, que, constitucional e legalmente, deveria ser gerida assim.

Entretanto, o fato de o projeto ser de camadas médias e apresentar nível relativamente elevado de participação (pelo menos mais alto que na escola pública) não deve conduzir a subestimar as comunidades de baixa renda. A literatura apresenta evidências de projetos sociais bem-sucedidos, inclusive ao criar raízes e continuidade, em grande parte porque são participativos. O capital social das populações pobres com freqüência é rico e pode contribuir para este sucesso, ainda que se reconheçam os riscos de cooptação destas populações, como o clientelismo. As organizações empresariais - e não só os projetos sociais - também se tornam mais abertas e participativas, com o compartilhamento do poder organizacional (Kliksberg, 2003). Será então o cooperativismo, nascido no século 19, apesar de todas as suas contradições (ou exatamente por elas, caso se considere que a história brota das contradições), um caminho significativo e promissor para o século 21? 


\section{Referências bibliográficas}

BRASIL. Lei $\mathrm{n}^{\circ}$ 5.764, de 16 de dezembro de 1971. Define a Política Nacional de Cooperativismo, institui o regime jurídico das sociedades cooperativas e dá outras providências. Disponível em: < https://www.planalto.gov.br/ccivil_03/Leis/L5764.htm> . Acesso em: 2 out. 2006.

BRASIL. Ministério da Educação. Secretaria de Educação Média e Tecnológica. O custoaluno no ensino médio. Brasília: MEC/Semtec, [2002].

CAMACHO, Carlos Galeão. Uma cooperativa de trabalho. Brasília: GH Comunicação Gráfica, 1997.

CARNEIRO, Palmyos Paixão. Cooperativismo: o princípio cooperativo é a força existencial-social do trabalho. Belo Horizonte: Fundec, 1981.

COLOZZI, Ivo. Le nuove politiche sociale. Roma: Carocci, 2002.

FROLA, Francisco. A cooperação livre. Rio de Janeiro: Athena, 1937.

GABBI, Elisabete Vincensi. A cooperativa educacional e seus dilemas: trajetória institucional e histórica da Escola Cooperativa de Piracicaba (1993-2000). Campinas, 2001. Dissertação (Mestrado em Educação) - Universidade Estadual de Campinas, Campinas, 2001.

GOMES, Candido Alberto. A educação em novas perspectivas sociológicas. 4. ed. São Paulo: Editora Pedagógica e Universitária, 2005.

INTERNATIONAL CO-OPERATIVE ALLIANCE. Statement of the Co-operative identity. Disponível em: <http://www.coop.org/coop/principles.htm>. Acesso em: 2 out. 2006.

KLIKSBERG, Bernardo. Por uma economia com face mais humana. Brasília: Unesco, 2003.

KLIKSBERG, Bernardo. Más ética, más desarrollo. 3. ed. Buenos Aires: Tema, 2004.

KRUEGER, Richard A. Focus groups: a practical guide for applied research. 2. ed. Thousand Oaks, Califórnia: Sage, 1998.

LERBET, Jacques. É possível para além da oposição entre causalidade e sentido? HADJI, Charles; BAILLÉ, Jacques (Org.). Investigação e educação: para uma "nova aliança". Porto: Porto Ed., 2001. p. 197-216.

LÜDKE, Menga; ANDRÉ, Marli E. D. A. Pesquisa em educação: abordagens qualitativas. São Paulo: Editora Pedagógica e Universitária, 1986.

LUZ FILHO, Fábio. Cooperativas escolares. 5. ed. Brasília: IBGE, 1960.

MOTA, Ivany Maria de Assis. Gestão educacional: arquitetura das relações humanas e exercício de poder na escola cooperativa. Campinas, 2003. Dissertação (Mestrado em Educação) - Universidade Estadual de Campinas, 2003.

NASCIMENTO, Fernando Rios do. Cooperativa educacional: alguns aspectos. Salvador: OCEB, [19—?].

ORGANIZAÇÃO DAS COOPERATIVAS BRASILEIRAS. Anuário do cooperativismo brasileiro. Brasília: OCB, 2000. 
PASQUINI, Antônio Carlos da Silva. Unidade e disciplina nas cooperativas de ensino. In: SEMINÁRIO SOBRE COOPERATIVISMO DE ENSINO, 1992, Brasília. Diretrizes para o desenvolvimento e a capacitação de cooperativas de ensino. Brasília: Banco do Brasil, 1992. p. 18-34.

PATTON, Michael Quinn. How to use qualitative methods in evaluation. Newbury Park, Califórnia: Sage, 2000.

PINHO, Diva Benevides. O pensamento cooperativo e o cooperativismo brasileiro: manual de cooperativismo. São Paulo: CNPq, 1982. v. 1.

RIBEIRO, Marlene. Organizações cooperativas de agricultores e educação escolar: desafios a uma formação cooperativa. Perspectiva, Florianópolis, v. 22, n. 1, p. 167-194, jan./ jun. 2004.

ROMANELLI, Otaíza de Oliveira. História da educação no Brasil: 1930/1973. Petrópolis: Vozes, 1978.

XAVIER, Antônio Carlos da R.; AMARAL SOBRINHO, José; MARRA, Fátima (Org.). Gestão escolar: desafios e tendências. Brasília: Ipea, 1994.

Gerrá Leite Correia de Araújo, mestre em Educação pela Universidade Católica de Brasília (UCB), é professor e ex-gestor escolar da rede pública do Distrito Federal.

Candido Alberto Gomes é professor titular fundador da Universidade Católica de Brasília (UCB).

cgomes@pos.ucb.br

Recebido em 5 de maio de 2006.

Aprovado em 6 de outubro de 2006. 